\title{
Resenha: AS NOITES DE CARMEM MIRANDA
}

\author{
Débora T. Mutter da Silva ${ }^{1}$
}

A vaga silenciosa e crescente de publicações dedicadas à vida de personalidades dos mais variados segmentos sociais é um fenômeno que, embora não seja exclusivo da literatura, tende a invadir os estudos literários. O cenário deve-se ao grande número de obras que se organizam em torno de biografias reais, inventadas ou híbridas e conquistam cada vez mais espaço no âmbito dos estudos culturais de ênfase revisional devido aos aspectos históricos implicados.

Nomes da política, da imprensa e das artes em geral armam uma constelação que altera discreta, mas profundamente, o conjunto de informações compartilhadas por determinados grupos humanos acerca de tais personalidades e de seus respectivos contextos. Algumas obras apóiam-se no aspecto pitoresco ou heróico de personalidades que acendem a imaginação dos leitores. Entretanto, dependendo da pergunta que o autor tenta responder, da profundidade da pesquisa e do discurso que subsidiou a escrita, a obra carrega, no seu íntimo, certa resistência identitária.

É nessa perspectiva que considero o romance intitulado "As noites de Carmen Miranda”, da escritora chilena Lucía Guerra. Publicado em espanhol, pela editora Sudamericana, Buenos Aires, no ano de 2002, a obra tem o dom de instigar os brasileiros, pois revela aspectos comoventes pela perspectiva humana dessa escritora, crítica literária e intelectual que se dedica às causas femininas. Autora de obras teóricas como "La mujer fragmentada" e de contos, como é o caso do livro intitulado "Frutos extraños”, ambos pela editora Cuarto Próprio, no Chile, Lucía Guerra empreendeu uma longa pesquisa sobre a vida de uma ilustre brasileira.

Antes de avaliar as suas motivações culturais, afetivas e intelectuais para empreender o projeto, considero a obra em seus aspectos formais. A diegese abarca toda a existência de Maria do Carmo Miranda da Cunha (09-02-1909 - 1954), a artista nascida em Portugal que ficou conhecida como Carmen Miranda, a brasileira mais bem paga de Hollywood entre os anos 40 e 50 do século XX. Veio para o Brasil com a família seguindo o sonho do pai, um imigrante português que, fugindo da miséria na Península, sonhava com as riquezas do gigantesco Brasil. A frustração da família, ao deparar-se com a fantasiosa expectativa de enriquecer, derivou, no plano concreto, para uma vida miserável como a de tantos brasileiros nas primeiras décadas do século passado no Rio de Janeiro. A jovem Carmen, entretanto, com sua capacidade artística e seu caráter conquistou o um lugar ímpar no cenário artístico nacional e internacional à época.

A narrativa tem como pano de fundo histórico tanto a realidade social e política brasileira, como a norte-americana, no período que envolve as duas Guerras Mundiais. Os efeitos de tais contingências na política e nas estratégias de ambos os países para enfrentarem as dificuldades comparecem no universo ficcional. Os choques culturais abafados em nome dos interesses comerciais e políticos, bem como a atuação destes nos bastidores do mundo artístico e suas consequências dramáticas quando contrariados são enfatizados na ficção, norteando a trajetória da protagonista. O mesmo ocorre com

\footnotetext{
${ }^{1}$ Doutor em Estudos de literatura brasileira e luso-africana; mestre em literatura comparada pela UFRGS e professor na Universidade Luterana do Brasil. E-mail deboramutter@terra.com.br Linha de pesquisa Cnpq: Literatura, estudos Culturais e História contemporânea.
} 
relação à indústria cinematográfica norte-americana e tudo que ocorre fora dos cenários, ou seja, detrás das câmeras. Uma arte que, afinada com o discurso político, desejava mostrar apenas diversão a um povo que precisava esquecer a depressão econômica e os efeitos das guerras. O preconceito velado ou acintoso aos sul-americanos remete a uma realidade persistente que se intensifica nas relações culturais entre o primeiro e o terceiro mundo. Colocando os holofotes sobre ações pouco glamorosas, Lucía Guerra revela as causas que levaram a artista brasileira a um exotismo tal que a sequestrou do sentido de pertencimento aos próprios brasileiros, ao mesmo tempo em que a impediu de ser acolhida pela rígida, tradicional e pragmática sociedade norte-americana, sua segunda pátria.

É assim que a escritora chilena, residente na Califórnia, representa a cisão de um ser dividido entre dois mundos, duas culturas, dois sonhos. Alguém que se tornou tão estrangeira no exterior quanto no seu próprio país, pois, cedendo às expectativas de uma sociedade cujo imaginário faminto de exotismo com relação ao Brasil crescia insaciável, acabou perdendo as referências culturais e identitárias. Isso fica evidente com relação ao vestuário e na perspectiva crítica da protagonista: "Los genios de la sección de vestuarios simple y sencillamente no sabían qué más inventar... lo espectacular, como cualquier otra cosa, se agotaba y mi traje de bahiana cada día se degradaba más y créanme que no estoy exagerando cuando digo esto [...] se habían ido transformando en un adefesio, en algo ridículo y extravagante” (GUERRA, 176).

A estrutura narrativa divide-se em cinco partes que correspondem cronologicamente às etapas da vida de Carmen Miranda. Essa regularidade, porém, desaparece no momento em que a voz de um narrador convencional, em terceira pessoa, é interpolada pela voz em primeira pessoa da protagonista em tom dialógico. A diferenciação tipográfica não apenas dessas duas vozes, mas de outras, além de evidenciar a complementaridade e a diversidade de fontes é uma forma de resistência ao discurso monolítico das biografias. Algumas vozes apresentam apenas a fonte tipográfica diferente (Mi papá murió el 6 de junio de 1938 y qué fácil es hablar de la muerte cuando se la reduce a una fecha - p. 79), outras, além do tipo gráfico, estão entre parênteses ((¡Mi pobre hermana y esse desígnio de infortúnio que nunca la abandonó! p. 50)) e ainda há aquelas que se distinguem por estar entre aspas ("Ni solo um minuto em Cuba dejamos de amarnos.” - p. 235). A opção imprime um ritmo sincopado à narrativa que dá ao leitor a impressão de estar acompanhando um documentário no qual falas e pensamentos da protagonista, bem como das demais personagens, entram para compor o arranjo. O conjunto se estabelece como uma série de micro-narrativas entrecortadas entre si que são suturadas pelo fio condutivo e pelas inserções do narrador, que se orienta no sentido de permitir ao leitor a construção de uma figura aparentemente isenta da submissão a uma única fonte. Há depoimentos reais de outras personalidades históricas que, junto com Carmen Miranda, compõem o ambiente narrativo no qual as referências cruzadas (RICOEUR, 2003) entre ficção e história preponderam. Os depoimentos de personagens reais são oriundos de outras biografias, por isso estão entre aspas. Trata-se de um jogo de intertextualidade que instiga o leitor a descobrir quais vozes são históricas e quais são ficcionais ou híbridas.

A inserção de fotografias de Carmen Miranda, à entrada, em cada capítulo, aliada à fragmentação das vozes narrativas, bem como suas idas e voltas ao passado são comuns nas autobiografias, pois encenam a fragmentação da memória, e isso ocorre no romance de Lucía Guerra. É como se a narradora concedesse à personagem um espaço para construir sua própria identidade, resistindo ao estereótipo em que se converteu. Assim, integrando a estrutura do romance forja-se, nas frinchas da ficção, uma espécie singular de autobiografia, que guarda afinidades parciais com a conceituação de 
Philippe Lejeune como relato retrospectivo em prosa que uma pessoa faz de sua própria existência, enfatizando sua vida individual e, em particular, a história de sua personalidade (LEJEUNE, 1998). Exceto pelo fato de que Phillippe Lejeune limita o seu conceito a uma pessoa real, a definição cabe à estratégia narrativa adotada por Guerra.

Essa opção contribui para caracterizar o texto de Lucía Guerra em sintonia com a estética pós-moderna não apenas do ponto de vista formal, mas, porque, além de problematizar a conclusão de qualquer hipótese sobre a questão dos gêneros textuais, faz da mistura destes a sua base, derrubando qualquer certeza sobre a facilidade de reconstrução de uma vida pela escrita. Outro item de pós-modernidade é a feição revisional via metaficção historiográfica, conforme o conceito de Linda Hutcheon (1991), pois acontecimentos históricos se revestem de outras nuances alterando a percepção do leitor.

Ao empreender seu projeto, a romancista foi primeiro pesquisadora, pois necessitou das mesmas ferramentas do biógrafo-historiador. Sua condição, porém, é mais cômoda, pois, embora seu compromisso seja como uma possível verdade, nunca será com a Verdade, posto que de antemão já a tem por inatingível. Com essa estratégia narrativa compósita de resíduos culturais e de memória, a romancista mostra que conhece o abismo que a separa do passado. E luta por colocar-se a salvo das armadilhas da parcialidade e da subjetividade. Porém, como essa é sempre uma empresa frustrada, em especial, se o objeto é uma personagem que ocupa um lugar no seu imaginário afetivo, o que se vê nas frinchas da ficção são as nuances de uma inserção do eu como é o caso da escritora chilena com relação à cantora brasileira.

Para romancear a vida real de Carmen Miranda, ela foi obrigada a ultrapassar a biografia e todas as suas vicissitudes como gênero que envolve um dilema ético por definição. A biografia é uma experiência dilacerante, pois o biógrafo sempre se esquiva do alvo quando pensa dele estar se aproximando. Os resíduos de uma vida são fogos fátuos que iluminam, obscurecem, sugerem, ocultam, convidando o biógrafo permanentemente a render-se à precariedade, à fragilidade do conhecimento adquirido. O ficcionista, assim como o biógrafo, sabe sempre que, em alguma medida, está cometendo uma invasão de privacidade, quando retira do biografado aquilo que ele manteve no seu íntimo, que confiou a fontes que, na sua intenção, jamais seriam consultadas.

Guerra, ao optar pela fragmentação e pela reunião de diversas vozes, mostra a consciência de que vasculhar a trajetória de uma vida exige um olhar sensível e ações cuidadosas. Ele enfrenta e resiste às fragilidades próprias da escrita biográfica que se pretende legítima, quando, concretamente, está sujeita a ocultar processos autobiográficos inconscientes.

Por seu caráter biográfico, o romance de Guerra insere-se na história, permitindo outra conexão teórica tangencial com o conceito de metaficção historiográfica (HUTCHEON, 1991), que a identifica em obras literárias que tomam fatos históricos para modificá-los, através da paródia ou da inserção de elementos e circunstâncias desconsiderados ou silenciados.

O certo, porém, é que a distância mínima que separa uma biografia de um romance que não se pretende biográfico acaba por levá-lo a exercer função semelhante. No caso de "Las noches de Carmen Miranda", isso ocorre justamente devido ao grau de aproximação que a autora estabelece consigo, com o narrador e com sua personagem. Algumas manifestações do narrador ingressam na subjetividade de pessoas reais, pois resultam da sua observação. Esse efeito de metalepse, que, efetivamente, consiste em intrusões passíveis de serem identificadas como da autora Lucía Guerra ocorre quando o 
narrador extradiegético adota a posição de testemunho e entra na interioridade das personagens através do monólogo e do estilo indireto livre. É também o caso de muitas das micro-narrativas inventadas para a protagonista: "Brillaba la fama y la fortuna en mi oficio siempre nochero... En periódicos y revistas se hablaba de mis éxitos junto a fotos donde yo sonreía plena de felicidad... pero tras esa felicidad se engarzaba también el infortunio como un collar de cuencas fúnebres... de llantos y sufrimientos.” (GUERRA, p.68)

Uma breve incursão pela biografia de Lucia Guerra mostra que a perspectiva da personagem-narrador se confunde, em alguns pontos, com a da autora real e, de certa forma, com sua vida. A escritora chilena, a exemplo da sua personagem Carmen Miranda, também experimentou a condição e as vicissitudes de ser uma latinoamericana na Califórnia. É este o caso quando a protagonista se refere às dificuldades com o idioma, pois reflete uma experiência da própria autora em sua extraterritorialidade. Essa incursão extratextual abre uma passagem para os planos de discursividade que habitam a narrativa. A aproximação parece ocorrer de forma proposital, a ponto de nos levar à formulação das seguintes questões: esse relato poderia corresponder parcialmente a uma autobiografia real? A composição estrutural é um desvio, a fim de brincar com os cânones estabelecidos para chamar a atenção para sua natureza inventiva e impossível de chegar a termo final?

A classificação de romance na ficha catalográfica dá ao leitor certa segurança, mas, ao final, e apesar de diferenças significativas com alguns dados reais da vida da artista brasileira, o romance instaura uma nova ordem no imaginário do leitor. O que se constata é que a literatura é ainda e sempre uma das práticas sociais que mais pode inseminar o espírito de resistência. E neste ano em que se comemora o centenário de nascimento da mulher, cujo sorriso e imagem conquistaram não apenas os americanos, mas também a Europa, essa narrativa introduz algumas questões sobre as discretas formas de resistência identitárias, além da ousada e instigante estrutura narrativa cuja composição lembra um pouco as exóticas e provocantes indumentárias de Carmen Miranda.

\section{REFERÊNCIAS}

GUERRA, Lucia. Las noches de Carmen Miranda. Bueno Aires: Sudamericana, 2002.

HUTCHEON, Linda. A Poética do Pós-Modernismo: história, teoria, ficção. [trad. Ricardo Cruz]. Rio de Janeiro: Imago, 1991. 331p.

JOSEF, Bella. (Auto)Biografia: os territórios da memória e da história. In: AGUIAR, F. (Org.) Gêneros de fronteira: cruzamento entre o histórico e o literário. São Paulo: Xamã, 1997, p. 297.

LEJEUNE, Phillippe. El pacto autobiografico. In: El pacto autobiografico y otros. El mundo iluminado. Ciudad del México: Lumen, 1998.

RICOUER, Paul. Tempo e Narrativa III. Campinas: Papirus, 2003. 